\title{
A Study of Evaluation Indices and Weight Comparison for Food Packaging Designs
}

\author{
Hui Chen \\ College of Art, Huaqiao University, Quanzhou, 362021, China \\ Shenghuo06@hqu.edu.cn
}

\begin{abstract}
In this study, a packaging design evaluation system has been built based on the design attributes, functional attributes, psychological attributes, and social attributes by following the scientific, objective, dynamic, and operable design evaluation principles via literature reviews and the investigation and analysis of data. A questionnaire survey was used for the investigation of the indicators, factors, and weights of each level of the evaluation system. The research subjects include two different populations consisting of 80 designers and 100 consumers respectively.
\end{abstract}

Keywords-Packaging design, design evaluation, analytic hierarchy process

\section{Introduction}

The general definition of design evaluation indicates carrying out evaluations or comparisons between single or multiple design schemes based on foundation of ideal product models or parameters in order to the confirm the quality or effects of a design scheme. The evaluation object could be a design concept, design scheme, and could also be a concrete design product. The evaluation span covers the entire process of product design, $R \& D$, production, and sales. It could happen at the concept formation during the earlier design stage or the actual evaluation and testing of samples and products during the final design stage. The effectiveness of the evaluation criteria is critical to an evaluation and it deals with the accuracy of the ideal evaluation model and parameters that have been built. Many scholars had investigated the topics that are related to packaging design evaluations from different directions and points of view. They considered the concept, content, and functions of a product package comprehensively based on the design evaluation principles so as to construct the packaging design evaluation system. Reasonable and adequate evaluation indices and factors are the foundation of the design evaluation system to be constructed and they are critical to the accuracy of the evaluation results. The evaluation factors of the current systems are obtained by a large number of questionnaire surveys on designers, enterprise personnel, and consumers. Based on this foundation, the investigated data is analyzed integrally by using a combination of quantitative and qualitative statistical approaches in order to verify the results. It has been found during the evaluation process that, there are differences to a certain extent between the feedbacks of the investigation data from concrete packaging designs or different investigation objects. Therefore, the investigation in this study started from two different types of investigation objects which include designer and consumers groups. The comparison and analysis were carried out by evaluating the design evaluation indices, factors, and weights of food packaging. The exact degree of influence for this type of influence was determined via graphs and it is expected that packaging design evaluation systems can be further improved to be more consummate via this study.

\section{Literature review}

In recent years, the study of packaging design evaluation has made some achievements and built some systems. It is expected to build a scientific, reasonable, objective, and accurate packaging design evaluation system for enterprises and designers. Some of the scholars proposed using the green packaging design evaluation method in the fuzzy set similarity measurement approach based on the green packaging design contents. This approach allows the investigation of the design strategy of green packaging and the analysis of green evaluation criteria from the design principles of the recycling and utilization of packaging[1]. On the other hand, with the fast development of eye movement experimental technologies, some scholars proposed using packaging design evaluation approaches based on eye movement experimental data[2][3]. By determining the visual elements of packaging design contents, the effectiveness of the transmission of packaging design information serves as the basis of packaging design evaluation. It is also equipped with evaluation applicability and feasibility to a certain extent[4]. Some of the studies are inclined to emphasize the principle of sustainability during the packaging design process. The strategic supportive approaches based on product life cycle are introduced into the design evaluation process in order to reduce design costs and enhance development efficiency[5]. Due to the complexity of design activities, a design evaluation needs to take the importance of subjective factors during the evaluation process sufficiently into account. More scholars carried out their studies from the standpoint of human-centered designs such as proposing the packaging design evaluation approach based on user experiences[6][7][8], user-friendly design evaluation approaches[9], emotional design evaluation approaches[10]. There are also other evaluation approaches which are capable of sufficient and definite evaluations on the importance of a product's packaging design based on concrete product attributes and consumer attributes[11][12][13][14][15].

\section{Methods}

\subsection{Selection of the packaging design evaluation approach}

Among them, the analytic hierarchy process (AHP) has the most extensive application. This is due to the fact that a packaging design evaluation problem is provided with complexity and fuzziness and it is difficult to resolve by simple quantitative analytical approaches. Therefore, the AHP approach is the most suitable one. This approach divides the corresponding critical factors of a packaging design into different levels which include goal, criteria, and alternatives. Via the quantitative and qualitative analysis of the indicating factors at each level, the relative importance of the indicating factors can be determined so as to 
build and calculate the judgment matrix. At the final stage, the composite weight of each indicating weight can be obtained via a consistency check. The main advantage of this approach is to highlight the hierarchical structure of the model for an evaluation system so that people can consider and evaluate the relative importance of the indicating factors sufficiently when carrying out an evaluation. The emphasis of this study is to determine and compare the changes in the weights of various indicating factors for evaluation for different types of people who carry out an evaluation. To this end, a questionnaire survey was implemented in this study to obtain the original data so that the AHP approach can be used to continue the follow-up analysis.

\subsection{Analysis of the subjects for investigation}

During the reviews in the questionnaire survey, the indicating factors of the packaging design evaluation serve as the main contents of this questionnaire. A total of 180 questionnaire copies were dispatched. Among them, 80 copies targeted the designer population for the questionnaire survey and 77 effective questionnaire copies were returned. The other 100 questionnaire copies were for the consumer population. The research subjects are described as follows.

(1) Population with 80 designers: There are 47 male designers (about 59\%) and 33 female designers (about 41\%). From the aspect of whether they received the design professional and fundamental courses or training, 19 of them are third-year and above college students (about 24\%), 22 designers with 1-3 years of working experience (about 28\%), 23 designers with 3-5 years of working experience (about 29\%), 16 designers with more than 5 years of working experience (about 20\%). There are 16 graphic designers (about 20\%), 11 industrial designers (about 14\%), 6 interior designers (about 8\%), 15 illustration designers (about 19\%), 10 animation designers (about 13\%), 12 color designers (about 15\%), 10 interaction designers (about 13\%). For their educational background, 56 of them are college and design-related students (about $70 \%$ ) and 24 of them are graduate students (about $30 \%)$.

(2) Population with 100 consumers: Among them, there are 47 males (about 47\%) and 53 females (about 53\%). Therefore, there are more females than males. For the distribution in age brackets, 35 of them are in the age of 20-30 (about 35\%), 42 of them are in the age of 31-40 (about 42\%), 23 of them are in the age of 41-50 (about 23\%). For their educational backgrounds, 38 of them are high school or below students (about 38\%), 47 of them are college students and design-related background (about $47 \%$ ), 15 of them are graduate or above students (about $15 \%$ ). Their occupations include 23 while-collar workers (about 23\%), 12 teachers (about 12\%), 20 homemakers (about 20\%), 23 workmen (about 23\%), and 22 sales persons (about $22 \%$ ).

\section{CONCLUSION}

By reviewing and analyzing a large number of earlier studies and data, a packaging design evaluation system which is based on the design attributes, functional attributes, psychological attributes, and social attributes as the fundamental contents by following the scientific, objective, dynamic, and operable design evaluation principles. The indicating factors and weights of each of the levels in an evaluation system were analyzed by approaches such as a questionnaire survey and the AHP approach. The subjects for this investigation include both the designer population and the consumer population. The original data was collected, categorized, and analyzed and the sum-product method was implemented for calculating the indicating weights at each of the levels of the evaluation system. The indicating weights of each of these two different populations were compared and analyzed for further investigation. Trend charts for the comparison of the indicating indices at various levels were drawn so that the common parts and different parts of the data from these two populations can be presented intuitively. The results of this study indicates that, Bothe the designer population and the consumer population have a higher degree of recognition for the first-level evaluation indicators in this system. This also indicates the overall evaluation content of the food packaging design evaluation system is effective and feasible with a correct direction. However, it was also found in this study that, these two populations have a certain degree of difference on the judgment of the weights of the second-level indicators in the evaluation system. The results also indicated that, during the process of evaluating a packaging design from different product categories or object populations, it is required to examine the effectiveness of each indicator in the evaluation system, followed by verifying the weight of each indicator integrally. This way the accuracy of the evaluation can be guaranteed.

\section{Reference}

[1] Zhang, J. F., \& Liang, L., Evaluation method for green packaging design based on vague set. Packaging Engineering.2007.

[2] Clement, J., Visual influence on in-store buying decisions: an eye-track experiment on the visual influence of packaging design. Journal of Marketing Management, 23(9-10), 2010, 917-928.

[3] Zhao, W., Zheng, L., \& Wang, T., Usability Evaluation of Packaging Design Based on Eye Movement Experiment. 2013 2nd international conference on science and social research (Vol.64, 2013, pp.626-629).

[4] Jurecic, D., Babic, D., \& Vancina-Kropar, V., Evaluation of information visual elements on the graphic design of packaging. Annals of Daaam for \& Proceedings, 110(50), 2005, 25322-25331.

[5] Kengpol, A., Buddeejeen, J., \& Tuominen, M., The packaging design approach and evaluation process by integrating iso/tr 14062 in a decision support methodology. , 7(2), 2014, 73-84.

[6] Lin, M. C., Chen, M. S., Lin, Y. H., \& Hung, Y. C., A user-centric evaluation procedure for the design of child-resistant medicine bottles. Human Factors and Ergonomics in Manufacturing \& Service Industries, 25(2), 2015, 211-227.

[7] Holmes, G. (2015). New Package Design: Evaluation of Consumer Experience. Revolution in Marketing: Market Driving Changes. Springer International Publishing.

[8] Li, X. N., \& Liu, H. L., Research on plm-oriented product design evaluation based on user experience. Key Engineering Materials, 693, 2016, 1905-1909.

[9] Huang, Y. J., Yan, A. M., \& University, C. S., Evaluation model of humanistic packaging design based on support vector machine. Packaging Engineering. 2015.

[10] Chen, X., Barnes, C. J., Childs, T. H. C., Henson, B., \& Shao, F., Materials' tactile testing and characterisation for consumer products' affective packaging design. Materials \& Design, 30(10), 2009, 4299-4310.

[11] Sansgiry, S. S., Cady, P. S., \& Sansgiry, S., Effect of package design on evaluation of otc medication information. Journal of Social \& Administrative Pharmacy Jsap, 18(1), 2001, 24-34. 
[12] Izumiya, A., Ohkura, M., \& Tsuchiya, F., The Evaluation of Pharmaceutical Package Designs for the Elderly People. Human Interface and the Management of Information. Information and Interaction. Springer Berlin Heidelberg. 2009.

[13] Becker, L., Rompay, T. J. L. V., Schifferstein, H. N. J., \& Galetzka, M., Tough package, strong taste: the influence of packaging design on taste impressions and product evaluations. Food Quality \& Preference, 22(1), 2011, $17-23$.

[14] Gil, I., Rebollar, R., Lidón, I., \& Martín, J., Study on the influence of fresh white cheese packaging design variables on users' perception. 2017.

[15] Krishna, A., Cian, L., \& Aydınoğlu, N. Z., Sensory aspects of package design. Journal of Retailing.2017. 